\title{
Building a Company Step by Step, Ch 6: Testing and Pivoting
}

Jon Eckhardt (University of Wisconsin-Madison)

KEYWORDS: Entrepreneurship, customer discovery.

EIX is featuring interviews that explore the principles outlined in Steve Blank and Bob Dorf's book, "The Startup Owners Manual: The Step-by-Step Guide for
Building
a
Great
Company."

(https://www.amazon.com/Startup-Owners-Manual-

Step-Step/dp/1119690684) This video interview and podcast

with Alex Yampolsky, co-founder and chief operating officer of Vytal Health,(https://vytalhealth.com) focuses on Chapter 6 of the book, which discusses the importance of testing your proposed product or service and knowing when to pivot.

Yampolsky's company, which delivers virtual visits with doctors and holistic health services to clients for a monthly fee, has pivoted from the founders' initial vision for it. While Yampolsky was trained as a pharmacist and wanted prescription drugs to be part of his company's services, he realized after testing that he couldn't compete in price with the big pharmacy chains. Vytal Health pivoted to supplements only, which involved an investment in more tools to help them fulfill orders. The company also pivoted from a fee-based service, which involved taking a cut of the fee for each doctor visit, to a subscription-based model, which cut his customer base in half. In this interview Yampolsky discusses these difficult decisions and others, and also how he has interpreted and implemented the advice in Blank and Dorf's book.

\section{Listen}

Link to video

\section{EIX}

(https://soundcloud.com/user-876519212-189256831).

Ch 6 Alex $\quad$ Yampolsky

(https://soundcloud.com/user-876519212-189256831/c

h-6-alex-yampolsky-v1-otter) 